\title{
비동기식 $\mathrm{MAC}$ 프로토콜 기반의 무선 센서 네트워크에서 단대단 시간 지연 성능 향상을 위한 멀티 홉 예약 기법의 제안
}

\author{
홍성화 ${ }^{{ }^{*},}$ 정석용 ${ }^{1}$ \\ ${ }^{1}$ 동양미래대학 전산학부

\section{A Multi-hop Reservation Method for End-to-End Latency Performance Improvement in Asynchronous MAC-based Wireless Sensor Networks}

\author{
Sung-Hwa Hong ${ }^{1^{*}}$ and Suk-Yong Jung ${ }^{1}$ \\ ${ }^{1}$ Division of Computer Science, Dongyang Mirae University
}

\begin{abstract}
요 약 긴 preamble을 사용하는 비동기식 MAC 프로토콜의 문제점을 개선하기 위해 나온 프로토콜이 X-MAC 이다. 본 논문에서는 X-MAC의 문제점을 해결하기 위하여 Express-MAC이라는 새로운 MAC프로토콜을 제안하였다. 무선 센서 네트워크는 주로 이벤트 데이터나 상황정보를 인지하는 목적에 많이 사용된다. 특히 침입감지 같은 이벤트 감지 를 목적으로 하는 센서네트워크의 전송 패턴은 매우 간헐적이면서도 한 번의 이벤트 발생 시 연속적으로 일어나는 것이 대부분이다. EX-MAC은 위와 같은 센서 네트워크의 주요 전송 패턴을 반영하여 첫 이벤트 발생 시 데이터 전 송에서 멀티 홉 경로의 채널 예약 및 awake 구간의 전송 시간 예약 방식을 사용하였다. 전송 경로상의 awake 시간 예약은 연속적인 데이터 전송의 단대단 지연 성능을 향상시켰으며 데이터 송수신 노드의 preamble 길이를 줄임으로써 에너지 소비 측면에서도 효율성을 증대시켰다.
\end{abstract}

\begin{abstract}
X-MAC reduces transmission delay and energy consumption by using a short preamble instead of the existing long preamble. To solve the problem of X-MAC, this paper proposes a new MAC protocol called Express-MAC. The wireless sensor network is mainly used for the purpose of gathering event data or situation information. Especially, the transmission pattern of the sensor network with the purpose of event detection such as intrusion detection is very intermittent as well as successively occurring when a single event takes place in most cases. By reflecting sensor network's key transmission patterns as above, EX-MAC has used multi-hub path's path reservation system and awake section's transmission time reservation method in data transmission when the first event takes place. The awake time reservation in transmission path has improved successive data transmission's end-to-end delay, and it has also increased efficiency in terms of energy consumption by reducing the preamble length of data transmission and reception node.
\end{abstract}

Key Words : Sensor network, MAC, Ubiquitous, Energy

\section{1. 서론}

하드웨어 기술의 향상으로 인한 저전력, 저비용의 센 서 노드 개발은 무선 센서 네트워크라는 새로운 통신 유 형을 탄생시켰다. 다른 무선 네트워크와는 달리 센서 네 트워크는 배터리 소모로 인한 재충전 및 교체 등의 적용
이 어렵다. 따라서, 구동 시간이 최소 수개월에서 최대 수 년간의 긴 수명이 요구된다. 이런 무선 센서 네트워크의 저전력 특성은 MAC(Medium access control) 계층에서도 가장 중요한 이슈가 되어왔으며 주로 duty-cycle을 사용 한 $\mathrm{MAC}$ 프로토콜이 사용되어 왔다[1,2].

Duty-cycle을 사용한 MAC 프로토콜은 주기적으로

*교신저자 : 홍성화(shhong@dongyang.ac.kr)

접수일 10년 05월 06일 수정일 10년 05월 25일 게재확정일 10년 07월 06일 
sleep와 awake를 반복하는 방식이다. Duty-cycle의 길이 는 센서 노드의 sleep과 awake 구간을 합한 길이와 같으 며 sleep 구간에서는 데이터 통신이 불가능하고, awake 구간에서만 데이터 통신이 가능하다. 에너지 소모는 센서 노드의 sleep 구간과 awake 구간 모두에서 소모되지만, sleep 구간에서는 구동에 필요한 최소의 에너지만 소모되 며 awake 구간에서는 Idle listening[3]을 사용하여 통신에 필요한 실질적인 에너지만 소모된다. Duty-cycle을 사용 한 무선 센서네트워크 $\mathrm{MAC}$ 프로토콜의 에너지 절감 효 과는 [4]에서 논의되어있다. 이런 duty-cycle을 사용한 $\mathrm{MAC}$ 프로토콜은 높은 수율과 낮은 지연, 높은 에너지 효율성을 이루기 위하여 데이터 전송량과 전송 패턴에 따라 다양한 설계 방식이 연구되고 있다.

본 논문에서는 X-MAC의 문제점을 해결하기 위하여 EX-MAC(Express-MAC)이라는 새로운 MAC 프로토콜을 제안하였다. 무선 센서 네트워크는 주로 이벤트 데이터나 상황정보를 인지하는 목적에 많이 사용된다. 특히 침입감 지 같은 이벤트 감지를 목적으로 하는 센서 네트워크의 전송 패턴은 매우 간헐적이면서도 한 번의 이벤트 발생 시 연속적으로 전송하는 것이 대부분이다. EX-MAC은 위와 같은 센서 네트워크의 주요 전송 패턴을 반영하여 첫 이벤트 발생 시 데이터 전송에서 멀티 홉 경로의 채널 예약 및 awake 구간의 전송 시간 예약 방식을 사용한다. 전송 경로상의 awake 시간 예약은 연속적인 데이터 전송 의 단대단 지연 성능을 향상시켰으며 데이터 송수신 노 드의 preamble 길이를 줄임으로써 에너지 소비 측면에서 도 효율성을 증대시킨다.

본 논문의 구성은 1 장의 서론에 이어 2 장에서는 관련 연구인 센서 네트워크 MAC 프로토콜에 대해 설명하였 다. 3장에서는 제안한 프로토콜에 관해 설명하고 4장에 서는 제안된 알고리즘에 대해 설명하고, 성능분석을 통해 제안된 알고리즘을 검증 할 것이고, 마지막으로 5 장에서 결론을 도출 할 것이다.

\section{2. 관련 연구}

무선 센서 네트워크에서 duty-cycle을 사용한 MAC 프 로토콜은 크게 나누어 3 가지 방식으로 구분 된다. 동기 방식과 비동기 방식, 그리고 이를 결합한 하이브리드 방 식이다. 동기식 MAC 프로토콜은 데이터 통신이 이루어 지는 그룹 간에 시각 동기 방식을 이용하여 awake 구간 을 동기시키는 방식으로 S-MAC[8], T-MAC[9], $\mathrm{DMAC}[10]$ 등이 포함된다. 비동기식 MAC 프로토콜은 시각 동기를 이용하지 않는 방식으로 preamble sampling
을 사용하며 B-MAC[11], WiseMAC[12], X-MAC[13] 등 이 대표적이다. 하이브리드 방식을 사용한 MAC 프로토 콜은 전송 패턴에 따라 동기 방식과 비동기 방식을 모두 사용하는 방식으로 Z-MAC[5] 등이 있다.

Preamble sampling을 사용하는 비동기식 MAC 프로토 콜의 주요 구동방식은 다음과 같다. 센서 네트워크에 포 함되는 모든 센서 노드들은 자신의 duty-cycle이 각각 개 별적으로 동작하며, awake/sleep 동기화를 위한 오버헤드 가 필요 없는 장점이 있다. 하지만 송신 노드가 수신 노 드의 awake 상태를 인지할 수 없기 때문에 sleep 구간만 큼의 preamble을 전송하여 수신노드를 awake 상태로 전 환시킨 후 데이터를 전송시킨다.. 이 때, 데이터 전송을 위한 preamble 사용은 다음과 같은 문제가 존재한다. 첫 째로, 긴 preamble 사용으로 인한 송수신 노드 간의 에너 지 비효율성이다. 비록 수신노드가 송신노드의 preamble 구간의 첫 부분에서 구동된다 하더라도 송신노드는 이를 인지하지 못하면, sleep 구간 길이만큼의 preamble 전송 이 불가피하다. 둘째로, preamble 전송으로 인한 오버히 어링 문제가 있다. 송신 노드의 preamble 전송은 데이터 수신 노드가 아닌 다른 노드에게도 preamble로 인식되기 때문에 데이터를 전송하지 않는 노드라 할지라도 preamble을 수신하게 되면 데이터 송수신 구간까지 awake 상태를 유지해야 하는 비효율성이 존재한다. 마지 막으로, 멀티 홉 환경에서 높은 단대단 지연이 존재한다. Preamble 전송으로 인하여 한 홉 당 데이터 전송 지연은 duty-cycle의 sleep 구간에 해당된다. 특히 이는 멀티 홉 환경에서 단대단 지연을 크게 증가시키는 결과를 야기 시킨다.

긴 preamble을 사용하는 비동기식 MAC 프로토콜의 문제점을 개선하기 위해 나온 프로토콜이 X-MAC[13] 이 다. X-MAC은 기존의 긴 preamble 대신 단시간의 preamble을 사용하여 전송 지연과 에너지 소비를 감소시 키는 효과를 가져왔다. X-MAC은 short preamble에 수신 노드의 $\mathrm{ID}$ 를 포함시켜 수신 노드가 아닌 노드가 preamble을 수신할 경우 자신이 전송에 참여하지 않는다 는 것을 알게 함으로써 빠른 sleep 상태로의 전환을 가능 하게 하였다. 또한 early ACK 사용으로 송신 노드가 수 신 노드의 awake 상태를 빠르게 파악하여 필요 없는 preamble 송수신을 제거시켰다. 또한 early ACK의 사용 은 홉당 전송 지연을 줄이는 효과를 가져왔다.

이와 같은 X-MAC의 개선에도 불구하고 다음과 같은 문제점이 존재한다. X-MAC의 short preamble 구간의 길 이는 평균적으로 sleep 구간의 절반만큼 소요된다. $\mathrm{X}-\mathrm{MAC}$ 이 기존 비동기식 $\mathrm{MAC}$ 프로토콜의 단대단 지연 성능을 개선하였지만 에너지 효율성을 위한 긴 sleep 구 
간으로 인하여 멀티 홉 환경에서 무시하지 못할 정도의 단대단 지연이 발생한다. 또한 연속적인 데이터 전송에서 지속적인 preamble 사용은 불필요한 에너지를 소비시킨 다.

\section{3. 제안 알고리즘}

센서 네트워크는 감시정찰, 침입감지, 화재경보, 안전 감시 등의 상황 보고 및 이벤트 감지 분야에 많이 이용된 다. 이와 같은 센서 네트워크의 특징은 서버나 싱크 노드 에서 하위 노드 방향의 다운링크 데이터 보다 하위 노드 에서 싱크 노드 방향의 업링크 데이터가 주를 이룬다. 또 한 이벤트가 일어나는 주기는 매우 간헐적이고, 이벤트 발생은 처음 이벤트가 발생된 지역 주변에서 연속적으로 발생되는 경우가 대부분이다. 이는 침입감지, 감시정찰, 위험 상황 보고 등을 위한 WSNs의 가장 큰 특징 중에 하 나이며, 그 이벤트 보고는 서버로의 빠른 데이터 전송이 요구된다. 하지만 에너지 효율성을 위한 duty-cycle을 사 용한 MAC 프로토콜은 단대단 지연 측면에서 그리 효율 적이지 못하며 X-MAC도 마찬가지로 멀티 홉 환경에서 단대단 지연이 높은 문제점을 가지고 있다.

본 논문에서는 duty-cycle을 사용하는 X-MAC의 긴 단 대단 지연 문제를 개선하였다. 제안하는 프로토콜은 멀티 홉 환경의 무선 센서 네트워크에서 전송 경로의 채널 예 약 방식을 사용하여 빠른 이벤트 데이터를 수집하도록 하였으며, 침입감지와 같이 이벤트 발생 원인이 이동하더 라도 기존 예약 경로를 이용하는 전송 경로 변경 방식으 로 빠른 데이터 전송을 가능하도록 하였다.

\subsection{EX-MAC}

Express-MAC (EX-MAC)의 특징은 다음과 같다.

- Duty-cycle을 사용한 비동기 MAC 프로토콜

- 높은 에너지 효율성

- 이벤트 데이터의 QoS 보장 및 낮은 단대단 지연

- 구현 용이성 및 낮은 오버헤드

보통 duty-cycle을 사용하는 비동기식 MAC 프로토콜 의 홉 당 지연은 sleep 구간에 해당하며 특히 멀티 홉 전 송에서 그 지연이 전송 홉 수에 비례하여 증가한다. 이는 preamble을 사용하는 비동기식 MAC 프로토콜의 가장 큰 단점이며 X-MAC도 이와 같은 문제점을 가지고 있다.

EX-MAC의 주 목적은 이벤트 발생 시에 사용자에게 빠른 데이터 전송과 높은 에너지 효율성에 있다.
EX-MAC은 X-MAC 프로토콜의 단대단 지연 성능을 개 선한 프로토콜로 이벤트 발생 시에 Event Data Reservation (EDR)을 사용하여 사용자에게 빠르게 데이 터 전송을 수행한다.

\subsection{EDR}

Event Data Reservation (EDR)은 지연이 홉 수에 비려 하게 증가하는 문제를 해결하기 위한 프로토콜로 이벤트 발생 시에 빠른 업링크 방향으로의 데이터 전송을 위한 전송 경로상의 채널 예약을 수행하는 방식이다. 따라서 매우 짧은 단대단 지연이 보장되며 짧은 길이의 preamble 사용이 가능하다. 이는 에너지 효율 증대뿐 아니라 다른 데이터 송수신에 영항을 최소화 시킬 수 있다. EDR방식 은 Event Data Parent Reservation (EDPR)과 Event Data Child Reservation (EDCR)의 2가지 방식이 있다.

\subsection{EDPR}

Event Data Parent Reservation (EDPR)은 고속의 데이 터 전송을 위한 부모 노드의 전송 채널 예약 방식으로 short preamble에 Counter field가 추가되어 동작한다. Counter field는 노드 자신과 자식 노드에 사용된 preamble의 개수를 나타내는 영역으로 자신의 데이터 전 송 시간을 부모 노드에 알리는 역할을 수행한다. EDPR 의 구동방식은 그림 1 과 같다.

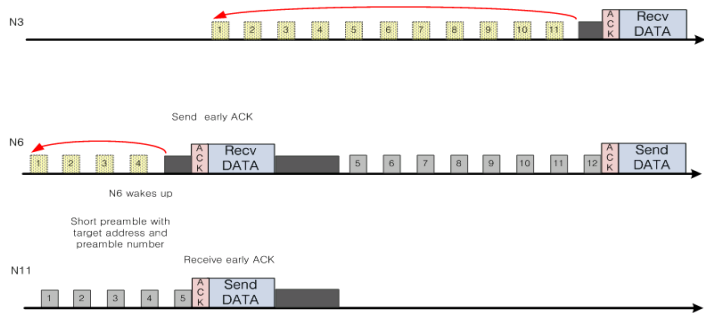

[그림 1] EX-MAC의 Event data parent reservation방법

첫 이벤트 발생 시 데이터 송수신 경로상의 모든 노드 는 Counter field 영역에 식 (1)와 같은 정보를 포함시켜 전송한다.

Preamble Counter $=$

전송 노드의 Preamble 수 + 자신의 Preamble 수 - 1

sleep길이만큼의 긴 preamble을 사용하는 대신에 여러 개의 short preamble을 사용함으로써 비동기 MAC 프로 
토콜의 오버히어링 문제를 해결하였다. EX-MAC은 여러 개의 short preamble 의 나열을 전송한다. Short preamble 에는 수신 노드의 ID 정보가 포함되어 있어 이를 수신한 노드는 preamble의 ID정보를 확인함으로써 자신이 관여 하지 않는 데이터 전송에서 자신의 상태를 빠르게 sleep 상태로 전환하는 방식으로 에너지 소모를 감소시켰다.

식 (1)의 정보는 이벤트 발생 노드 주기를 기준으로 하 여 경로상의 모든 노드의 awake 주기를 순차적으로 동기 화 시키는데 사용된다. Preamble counter는 최대 sleep 구 간에 해당하는 값을 넘을 수 없으며, 그 최대값 이상일 때에는 최대값으로 나눈 나머지가 사용된다. 기존의 예약 이 존재하지 않은 노드가 Counter field가 포함된 preamble을 수신하면 자신의 awake 시간을 (preamble counter - 1) 에 해당하는 시간만큼 이동시킨다. 이와 같은 과정으로 첫 데이터 전송과정에서 전송 경로상의 모든 노드는 이벤트 발생 노드 주기에 맞추어 주기가 변경되 며, 이어지는 이벤트 발생은 빠른 업링크 방향의 데이터 전송이 가능하다.

EDPR을 사용할 때 예약의 허가 여부는 수신 노드의 early ACK의 reservation permission field에 포함된다. 만 약 기존의 예약이 존재할 경우 부모노드의 주기 변경은 수행되지 않으며, 자식 노드의 주기가 변경되는 $\mathrm{EDCR}$ 이 수행된다. $\mathrm{EDCR}$ 은 예약이 존재할 경우 기존 예약의 전 송 주기 변경을 막기 위해 사용된다. EDPR로 예약된 구 간은 데이터 전송의 QoS 보장을 위해 백오프 과정 없이 수행된다. 예약의 유지는 마지막 데이터 전송 후 일정시 간이 지나면 초기화 된다. 초기화는 예약되었던 모든 노 드들이 임의의 시간으로 자신의 주기를 변경하는 과정을 수행한다. 일정 시간 후 예약 초기화는 새로운 이벤트 데 이터의 빠른 업링크 전송 예약을 가능하게 할 뿐 아니라 경로 예약 수행 후 다운링크의 높은 전송 지연 문제도 해 결한다.

\subsection{EDPR}

Event Data Child Reservation (EDCR)은 다른 노드의 기존 예약으로 인하여 EDPR이 불가능 할 때 이루어지는 awake 시간 변경 방식이다. 다른 노드의 기존 예약이 존 재할 경우, 새로운 노드의 이벤트 데이터 전송으로 인한 awake 시간 변경이 가능하다면, 기존 예약 노드의 데이 터 전송을 방해하여, 기존 예약 노드 데이터의 단대단 지 연을 늘어나게 하는 결과를 야기시킨다. 따라서 예약 초 기화 이전까지 EDPR의 중복은 불가능 하고 새로운 예약 방식으로 $\mathrm{EDCR}$ 을 사용한다.

EDCR은 early ACK에 child reservation field를 추가함 으로써 이루어진다. 그림 2 와 같이 부모 노드에서 early
ACK의 child reservation field가 1이면 early ACK를 받은 시간으로부터 데이터 전송에 필요한 시간을 제외하여 자 신의 awake 시간을 앞당기게 된다. EDCR은 상위 노드의 예약 방식으로 EDPR보다 우선시되어 예약되며 이전의 예약된 노드와 충돌을 예방하기 위해 백오프 과정 후 데 이터 전송을 수행한다.

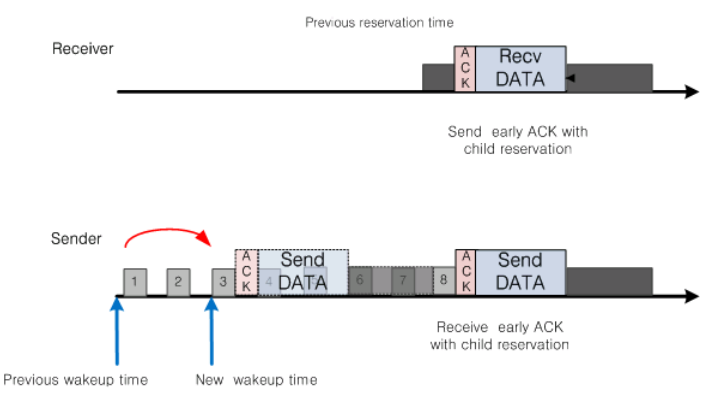

[그림 2] EX-MAC의 Event data parent reservation방법

$\mathrm{EDCR}$ 의 단점은, $\mathrm{EDPR}$ 이 한 번의 데이터 전송으로 전송 경로의 모든 노드의 주기 예약을 완료하는 반면, $\mathrm{EDCR}$ 은 상위 노드의 예약방식을 사용함에 따라 이벤트 발생 노드로의 홉 수만큼의 데이터 전송이 필요하다는 것이다. 하지만 $\mathrm{EDCR}$ 예약 과정 중이라도 그 단대단 전 송의 지연은 $\mathrm{EDPR}$ 을 사용한 기존 예약이 존재하므로 단 대단 전송에서는 1 홉 정도의 추가 지연 시간만이 소요된 다.

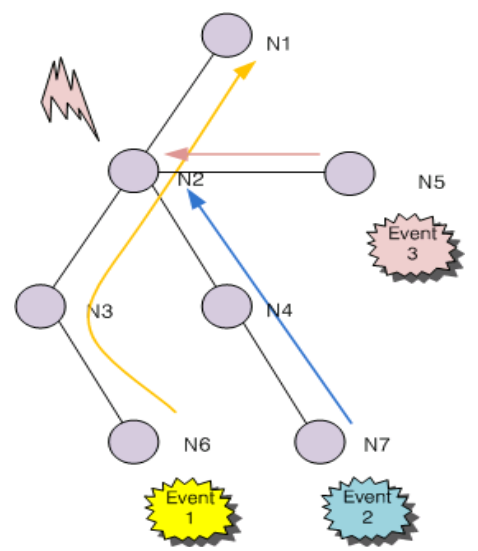

[그림 3] 트래픽 증가에 따른 전송 지연

$\mathrm{N} 2$ 은 이전의 이벤트 데이터 전송으로 N1으로의 전송 예약이 존재한다. 이 때 N7, N5에서의 이벤트 발생이 생 긴다면 N4와 N5 중 먼저 매체에 접근 가능한 노드는 N2 로 preamble을 전송한다. 따라서 N6는 정해진 시간에 데 이터 전송이 불가능하고, N4와 N5의 데이터 전송 후에 
N1으로의 데이터 전송을 수행한다. 하지만 N1은 이를 인 지하지 못하고, 자신의 예약 주기를 수행하기 때문에 다 음 주기가 되어야 N2로부터 N2와 N4, N5의 데이터를 수 신 받게 된다. 이는 데이터 전송 지연 문제뿐만 아니라 $\mathrm{N} 2$ 의 긴 preamble 전송으로 인하여 에너지 낭비가 발생 하고 다른 노드의 전송을 방해하는 요인이 되기도 한다. 이와 같은 문제를 해결하기 위하여 EX-MAC은 Waiting ACK과 Delay preamble 의 두 가지로 트래픽 증가에 따 른 전송지연 문제를 해결하였다.

EX-MAC의 전송 채널 충돌 예방은 기본적으로 Carrier Sense Multiple Access/Collision Avoidance $(\mathrm{CSMA} / \mathrm{CA})$ 의 랜덤 백오프 방식을 사용한다. 하지만 그 림 3의 네트워크 환경과 같이 예약된 경로의 노드가 데이 터 전송을 시도할 때, 예약 되어 있지 않는 노드의 데이 터 전송으로 인하여 채널이 사용 중이라면 단대단 전송 에 추가적인 지연이 발생된다. 이는 그림 4 에 나와있다.

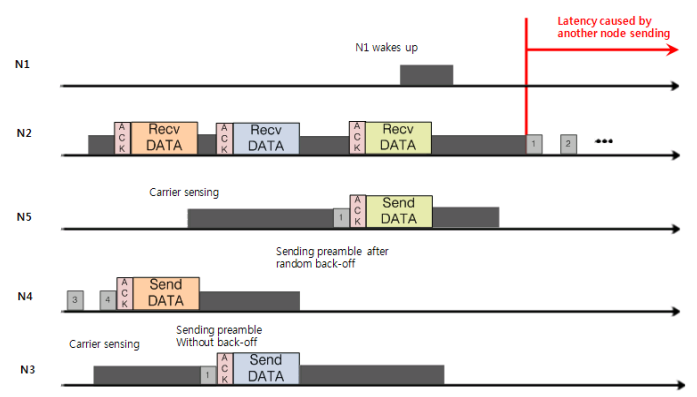

[그림 4] 트래픽 증가에 따른 예약 노드의 전송 지연

Waiting ACK는 트래픽 증가로 인하여 예약된 전송 시 간에 데이터 전송이 불가능할 때 사용된다. preamble 수 신시에 패킷 수신으로 인하여 예약된 시간에 전송이 불 가능하다고 판단되면 노드는 Waiting $\mathrm{ACK}$ 를 보내 패킷 전송을 막고 자신의 예약된 전송구간에 데이터 전송을 가능하게 한다. Waiting ACK 사용 후 preamble은 Delay preamble 정보를 포함시킨다.

Delay preamble은 트래픽 증가에 따라 예약 구간의 지 연이 필요한 경우에 사용한다. 트래픽 증가는 정해진 예 약 구간에 전송을 방해하는 요인이 되며, 단대단 지연을 늘어나게 하는 결과를 낳는다. Delay preamble은 전송 경 로 노드의 awake 시간을 패킷 송수신 단위만큼 지연 시 킴으로써 다음 주기부터 트래픽 상승에 따른 awake 구간 을 증가시켜 단대단 지연 증가를 막는다. Waiting ACK와 Delay preamble을 사용한 전송은 그림 5에 나와있다.

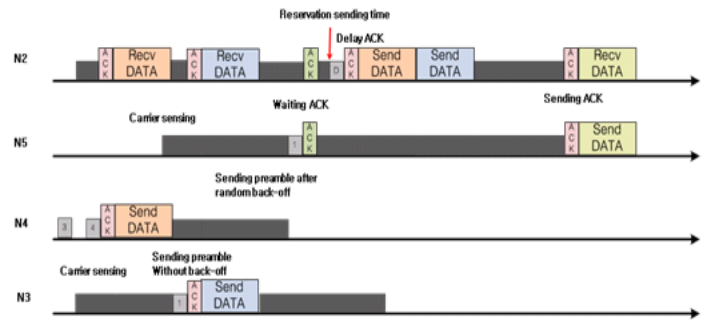

[그림 5] Waiting ACK와 Delay preamble을 사용한 전송 지연 해결

$\mathrm{N} 4$ 와 N3로부터 데이터를 수신 받은 N2는 N5의 preamble을 수신 받는다. 하지만 N2는 이전의 예약으로 인하여 정해진 시간에 N1으로의 데이터 전송이 불가능함 을 인지하고 Waiting ACK를 전송하여 N5의 이어지는 preamble 전송을 막는다. Waiting $\mathrm{ACK}$ 를 수신 받은 N5 는 N2의 ACK가 전송될 때까지 awake 상태를 유지한다. Waiting $\mathrm{ACK}$ 의 사용으로 $\mathrm{N} 2$ 는 정해진 시간에 $\mathrm{N} 1$ 으로 Delay preamble의 전송이 가능하게 된다. Delay preamble 에는 트래픽 증가에 따른 새로운 예약 구간이 포함되어 있으며 이는 다음과 같다.

Waiting ACK와 Delay preamble 사용 후 전송 경로 노 드는 자신의 예약구간의 지연을 수행하며 다음 주기부터 증가된 트래픽 상황에서도 빠른 데이터 전송이 가능하다. 다음 주기의 데이터 송수신은 그림 6 과 같다.

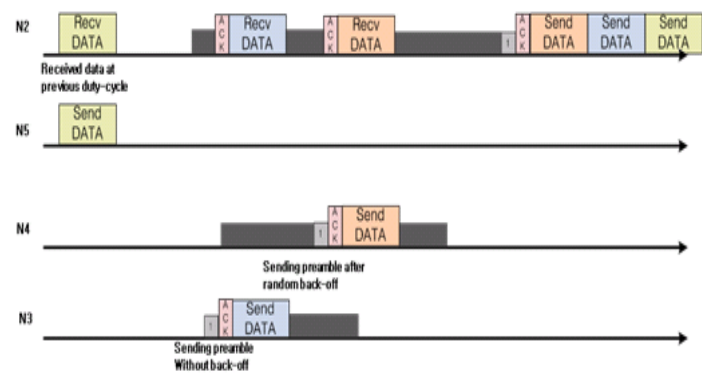

[그림 6] Waiting ACK와 Delay preamble 사용 후 데이터 송수신

본 논문에서는 $\mathrm{EDR}$ 을 사용하여 하나의 센서 노드에 서 연속적으로 일어나는 이벤트 데이터의 단대단 전송 지연 성능을 향상시켰다. 하지만 $\mathrm{EDR}$ 은 각 센서 노드의 첫 이벤트 데이터 전송에서 경로 노드의 주기 예약 수행 과정이 필요하다. 따라서 이벤트 대상의 이동이 발생할 때마다 높은 단대단 전송 지연이 나타나게 된다. 특히 침 입감지와 같은 위치 추적 시스템에서 대상의 이동마다 나타나는 높은 단대단 전송 지연은 센싱 지역의 실시간 상황 보고에 적합하지 못하다. 이와 같은 이동성 이벤트 
의 높은 전송 지연 문제를 해결하기 위하여 본 논문에서 는 Event Data Overhearing Process (EDOP)과 Event Data Stealing Process (EDSP) 두 가지 기법을 제시하여 기존 예약 경로를 이용하는 방식으로 사용자로의 빠른 전송이 가능하다.

\subsection{EDOP}

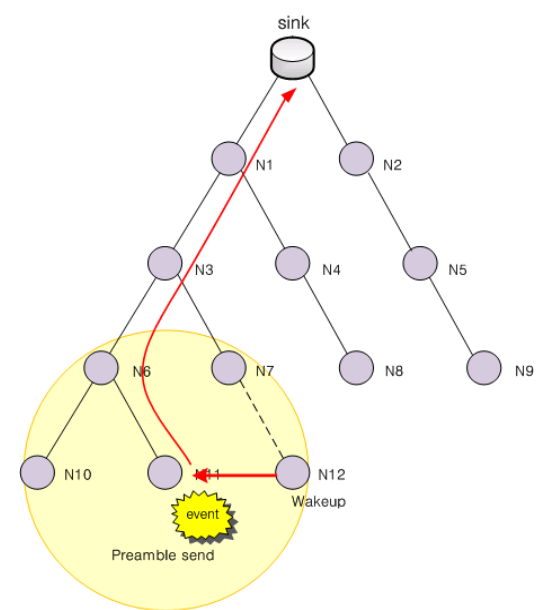

[그림 7] $\mathrm{EDOP}$ 를 사용한 전송 경로 변경

한 노드에서 이벤트가 발생할 경우 이웃 노드는 이벤 트 발생확률이 높아지게 된다. Event Data Overhearing Process (EDOP)은 이와 같은 이벤트 발생의 특징을 적용 하여 이웃의 노드들이 자신의 이벤트 발생 이전에 미리 이를 예측하여 기존 예약 경로를 이용하는 방식이다. $\mathrm{EDOP}$ 의 수행 과정은 그림 7과 같다. N11에서 첫 이벤트 가 발생하면 N11은 경로상의 주기 예약을 위하여 N6에 preamble을 전송한다. 이때 이웃의 노드 N12가 awake상 태로 전환되어 N11의 preamble을 수신하게 되는 경우 자 신의 부모 노드를 N7에서 N11로 변경한다. 이와 같은 부 모 노드의 변경은 추후 발생 가능성이 있는 이벤트 대상 의 이동에서 기존의 예약 경로를 사용하게 함으로써 표 적 이동에 의한 이벤트 데이터의 빠른 단대단 전송이 가 능하다. $\mathrm{EDOP}$ 과정을 통한 부모 노드의 변경은 임의 시 간 동안 유지되고 그 이후에는 부모 노드를 다시 N7로 변경시킨다. N11의 부모 노드 N6를 제외한 이웃 노드 $\mathrm{N} 7$ 과 N10에서도 $\mathrm{EDOP}$ 과정이 수행 가능하다.

$\mathrm{EDOP}$ 를 통한 부모노드 변경은 예약을 위한 preamble 전송 구간에서 이웃의 노드들이 이를 수신하게 될 경우 로 약 $50 \%$ 의 확률로 이웃 노드의 경로 변경이 이루어진 다. $\mathrm{EDOP}$ 를 통한 경로 변경은 예측성 경로 변경이기 때 문에 주기 예약과정은 수행하지 않는다.

\subsection{EDSP}

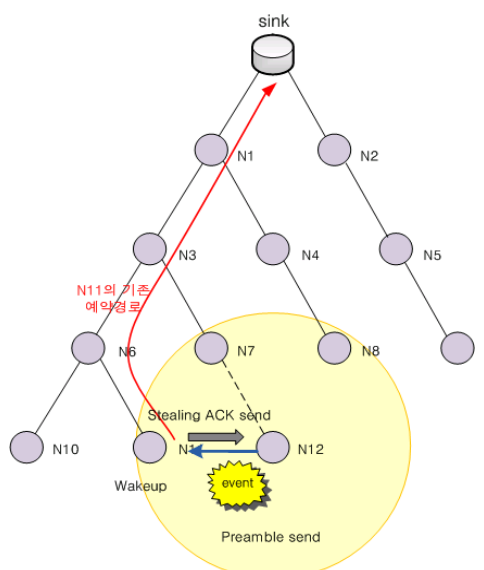

[그림 8] $\mathrm{EDSP}$ 를 사용한 전송 경로 변경

Event Data Stealing Process (EDSP)는 EDOP가 이루 어 지지 않았을 경우 사용된다. $\mathrm{EDSP}$ 는 빠른 데이터 전 송이 이루어지도록 하는 방식으로 그 구동방식은 그림 8 와 같다.

N12가 첫 이벤트를 감지한다면 전송 경로의 주기 예 약을 위해 N7로 preamble 전송을 수행한다. 이때 N7보다 먼저N11이 awake 상태로 전환된다면 N11은 N12로 Stealing ACK를 보내 자신의 경로가 확보되어 있음을 전 송한다. Stealing ACK를 통하여 N12는 이웃 노드인 N11 이 예약된 경로를 확보 하였음을 인지하게 되고 자신의 부모 노드를 N7에서 N11로 임의시간 동안 변경시킨다. $\mathrm{EDSP}$ 는 $\mathrm{EDOP}$ 와는 다르게 확실한 이벤트 감지 상황이 므로 $\mathrm{EDCR}$ 을 사용하여 자신의 전송 주기를 $\mathrm{N} 11$ 에 동기 화 시킨다. EDSP도 N12의 preamble을 N7보다 N11이 먼 저 수신하게 될 경우 발생하게 되므로 약 $50 \%$ 의 확률로 예약된 경로의 이용이 가능하다.

$\mathrm{EDSP}$ 는 자신이 이벤트 감지 노드가 아닌 전송 경로상 의 노드라 할지라도 이웃 노드의 예약 상황을 Stealing $\mathrm{ACK}$ 로 수신 받을 경우 자신의 부모 노드 및 예약 상황 의 변경 수행이 가능하다. 따라서 이벤트 감지 노드의 2 3홉 이내의 전송 경로 노드에서 부모 노드 변경 확률 이 증가된다.

$\mathrm{EDOP}$ 와 $\mathrm{EDSP}$ 의 성공 확률은 각각 $50 \%$ 이며 서로 독 립적이다. 따라서 한 홉에 대한 $\mathrm{EDOP}$ 와 $\mathrm{EDSP}$ 의 전체 성공확률은 약 $75 \%$ 가 된다.

\section{4. 성능 분석}

본 절에서는 제안한 프로토콜에 대한 성능평가를 위한 
시뮬레이션을 통하여 그 결과를 분석한다. 시뮬레이션은 $\mathrm{Matlab}$ 을 이용하여 분석하였고 S-MAC과 X-MAC을 그 비교 대상으로 하였다.

[표 1] 시뮬레이션 파라미터

\begin{tabular}{|c|c|c|c|c|c|c|c|}
\hline & & \multicolumn{2}{|c|}{ S-MAC } & \multicolumn{2}{|c|}{$X-M A C$} & \multicolumn{2}{|c|}{ EX-MAC } \\
\hline \multicolumn{2}{|c|}{ Data Fale } & \multicolumn{6}{|c|}{$256 \mathrm{kbps}$} \\
\hline \multicolumn{2}{|c|}{ Packe! Size } & \multicolumn{6}{|c|}{32 Byte } \\
\hline \multirow{4}{*}{\multicolumn{2}{|c|}{ Overfead Size }} & SYNC & 11 Byte & \multirow{2}{*}{ Proamble } & \multirow{2}{*}{7 Byte } & \multirow{2}{*}{ Preamble } & \multirow{2}{*}{11 Byte } \\
\hline & & ATS & 11 Byte & & & & \\
\hline & & CTS & 11 Byte & \multirow{2}{*}{ ACK } & \multirow{2}{*}{7 Byle } & \multirow{2}{*}{ ACK } & \multirow{2}{*}{11 Byle } \\
\hline & & $A C K$ & 11 Byte & & & & \\
\hline \multirow{3}{*}{$\begin{array}{l}\text { Erergy } \\
\text { Chipcon } \\
\text { CC1100 }\end{array}$} & $\begin{array}{l}\text { Transmisalon } \\
\text { Power }\end{array}$ & \multicolumn{6}{|c|}{$30.7 \mathrm{~mA}$ at $3.0 \mathrm{~V}$} \\
\hline & Rocedve Powner & \multicolumn{6}{|c|}{$16.4 \mathrm{~mA}$ at $3.0 \mathrm{~V}$} \\
\hline & Ide Power & \multicolumn{6}{|c|}{$900 \mathrm{nA}$ at $3.0 \mathrm{~V}$ (with WOR) } \\
\hline
\end{tabular}

시뮬레이션 실행 환경은 다음과 같다. 네트워크 크기 는 4 100개의 노드로 구성하였으며 각 노드의 센싱 범위 는 $25 \mathrm{~m}$ 로 하였다. 노드 배치는 그림 9 와 같이 센싱 범위 당 균일하게 배치하였고, 통신 범위는 $70 \mathrm{~m}$ 로 설정하였 다. 이는 노드의 참조 모델에서 권하는 권장 사항이다 [6,7].각 노드는 이벤트 발생 시 싱크 노드로 멀티 홉 데 이터 전송을 수행하고, 라우팅 방법은 시뮬레이션 초기에 싱크 방향으로 랜덤하게 설정하였다. 참조 모델은 Chipcon의 RF모듈인 CC1100을 사용하였으며 소모 에너 지와 전송 속도, 패킷 종류별 크기는 표 1에 나타내었다 $[6,7]$.

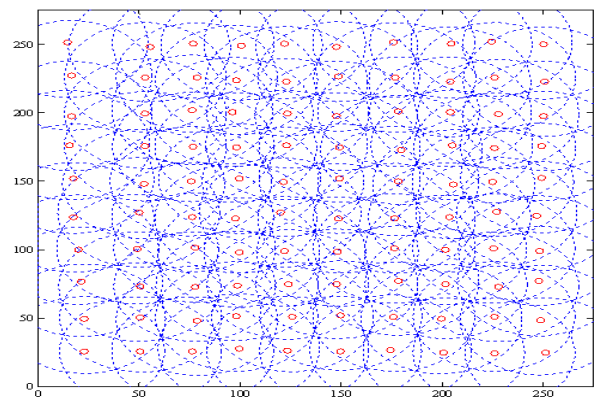

[그림 9] 시뮬레이션 네트워크 토폴로지

시뮬레이션 수행 방식은 다음과 같다. 첫째 네트워크 사이즈를 $2 \times 2 \sim 10 \times 10$ 으로 노드의 수를 증가 시키면서 전 송 패킷의 단대단 지연과 단위시간 당 노드의 소모 에너 지를 측정하였다. 노드의 sleep 시간은 $1000 \mathrm{msec}$ 이고, 이 벤트는 $(10,10)$ 지점의 노드에서 발생시켰다. 두 번째 시 뮬레이션은 10x10네트워크에서 sleep 구간을 200msec $1000 \mathrm{msec}$ 로 변화시키며 패킷의 단대단 지연을 측정하였
다. 세 번째 시뮬레이션은 $10 \times 10$ 네트워크에서 이벤트 표 적을 이동시켰을 때 단대단 지연성능을 측정하였다. 노드 의 sleep 시간은 $1000 \mathrm{msec}$, 첫 이벤트 발생은 $(10,10)$ 지 점이다. 이벤트 표적은 한번의 이동범위를 1홉 범위로 하 였으며 싱크 방향으로 랜덤하게 이동시켰다. 네 번째 시 뮬레이션은 랜덤하게 이동하는 이벤트 표적을 3 개로 증 가시킨 후 세 번째 시뮬레이션과 같은 환경에서 수행하 였다. 마지막 시뮬레이션은 $10 \times 10$ 네트워크에서 노드의 sleep 시간을 $1000 \mathrm{msec}$ 로 하였을 때, 패킷의 업링크/다운 링크의 단대단 지연 성능을 측정하였다.

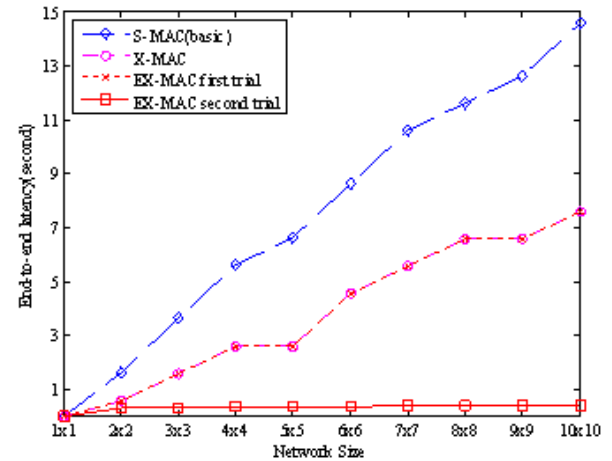

[그림 10] 멀티 홉 환경에서 네트워크 사이즈에 따른 패킷 의 단대단 지연

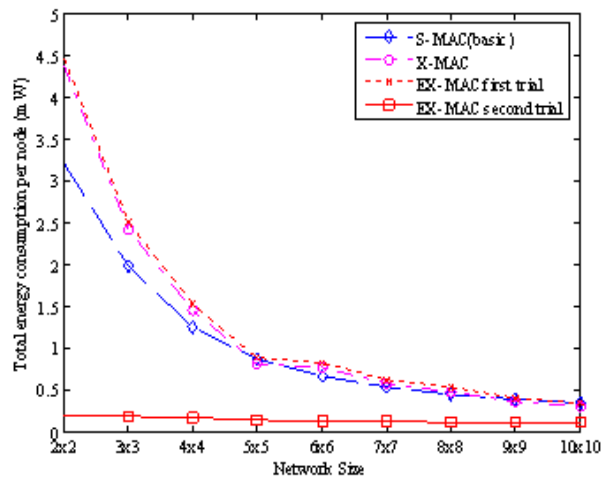

[그림 11] 멀티 홉 환경에서 네트워크 사이즈에 따른 단위 시간당 노드의 전송 에너지 소비

그림 10 은 네트워크 사이즈 변화에 따른 단대단 전송 지연 시뮬레이션 결과이다. S-MAC (basic)은 전송 홉과 노드의 sleep 길이에 비례하여 선형적으로 증가함을 알 수 있다. 또한 X-MAC은 S-MAC의 절반 정도의 단대단 전송 지연이 발생한다. $\mathrm{EX}-\mathrm{MAC}$ 은 첫 데이터 전송에서 $\mathrm{X}-\mathrm{MAC}$ 과 비슷한 단대단 전송 지연이 발생하였으며, 두 번째 데이터 전송에서 단대단 전송 지연이 네트워크 사 
이즈에 상관없이 1 홉 수준의 지연으로 감소되었다. 같은 환경에서 패킷 전송에 따른 노드 당 에너지 소비는 그림 11에 나와있다. X-MAC은 S-MAC보다 작은 네트워크 사 이즈에서는 높고, 큰 네트워크 사이즈에서는 비슷한 수준 의 에너지 소비를 보였다. EX-MAC은 첫 번째 데이터 전 송에서 추가적인 오버헤드로 인하여 X-MAC보다 약간의 높은 에너지 소비를 보였지만, 두 번째 전송부터 네트워 크 사이즈와 상관없는 적은 에너지 소비를 보였다. $\mathrm{EX}-\mathrm{MAC}$ 은 $5 \times 5$ 네트워크에서 X-MAC의 약 $20 \%, 10 \times 10$ 네트워크에서 약 $40 \%$ 수준의 에너지 소비를 보인다. 만 약 여러 번의 데이터 전송이 추가적으로 이루어질 경우, 에너지 소비는 X-MAC보다 월등하게 줄어들 것이다.

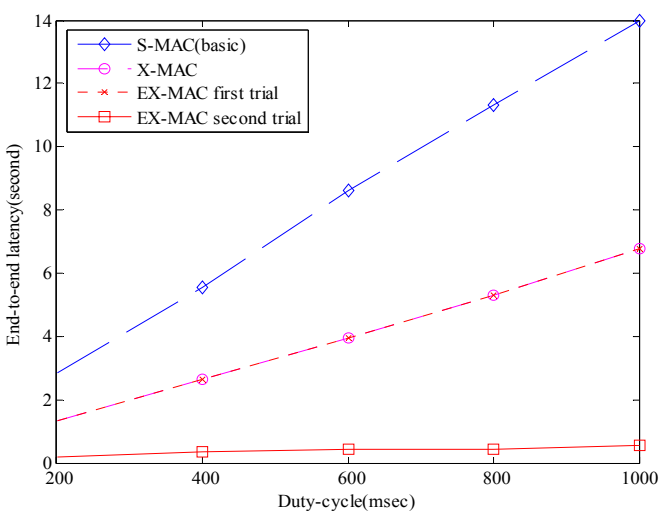

[그림 12] Duty-cycle에 따른 패킷의 단대단 지연

그림 12 는 sleep 구간에 따른 패킷의 단대단 전송 지연 결과이다. S-MAC은 sleep 구간과 비례하게, X-MAC은 sleep 구간의 절반에 비례하여, 단대단 전송 지연이 증가 하였다. EX-MAC은 첫 데이터 전송에서 X-MAC과 같은 단대단 지연을 보였지만, 두 번째 전송 이후 sleep 구간에 따라 데이터 전송에 필요한 시간 만큼의 아주 적은 전송 지연 증가를 보였다. 따라서 첫 이벤트 데이터가 중요하 지 않은 센서 네트워크 응용 분야에서는 좀 더 긴 sleep 구간 사용으로 에너지 효율성 증대가 가능하다.

그림 14 는 이벤트 표적의 이동에 따른 단대단 지연 결 과이다. 이벤트 표적의 이동경로는 그림 13 와 같다. $\mathrm{S}-\mathrm{MAC}$ 은 표적 이동에 따른 평균 단대단 지연이 약 9 초, $\mathrm{X}-\mathrm{MAC}$ 은 약 5 초 정도의 평균 지연 시간을 보였다. $\mathrm{EX}-\mathrm{MAC}$ 은 $(10,10)$ 지점의 첫 이벤트에서 X-MAC과 같 은 평균 지연 시간이 소요되었지만, 이어지는 표적 이동 이벤트에서 약 1.2 초 정도의 평균 지연 시간을 보였다. 이는 $\mathrm{EDOP}$ 와 $\mathrm{EDSP}$ 의 사용으로 인하여 이벤트 발생지 점의 약 1 2홉 구간에서 기존 예약구간으로의 경로 변경
이 이루어졌음을 알 수 있다.

$(7,5)$ 지점에서 약간의 전송지연 상승이 있었지만 다시 이어지는 이벤트 표적 이동에서는 낮아지는 단대단 지연 이 확인 가능하다. 이는 $\mathrm{EDOP}$ 와 $\mathrm{EDSP}$ 의 성공 확률이 $75 \%$ 이기 때문에 발생한 것으로 예상되며 첫 이벤트 $(10,10)$ 에서 거리가 멀어짐에 따라 4 5홉 정도 떨어진 노 드에서 새로운 예약이 수행된 것으로 보이며, $(6,4)$ 구간 이후부터는 $(7,5)$ 의 이벤트 예약 경로를 통하여 빠르게 단대단 전송이 이루어진 것으로 예상된다. 만약 이벤트 이동이 $(10,10)$ 지역 주변으로만 이루어진다면 S-MAC, $\mathrm{X}-\mathrm{MAC}$ 과 비교하여 아주 작은 수준의 단대단 지연 성능 이 보장 될 것이다.

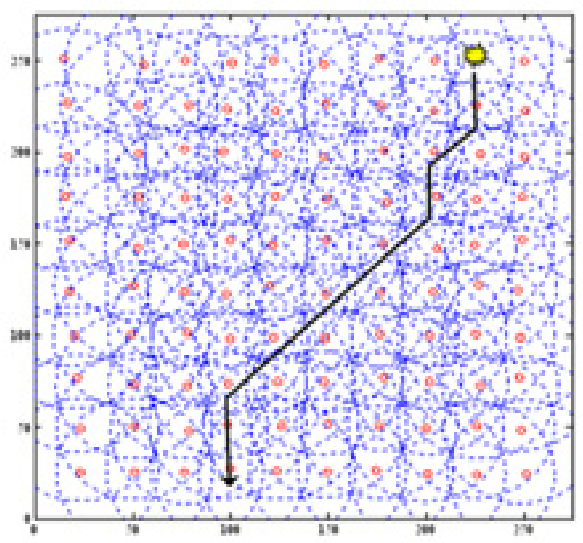

[그림 13] 이벤트 타겟 이동 경로

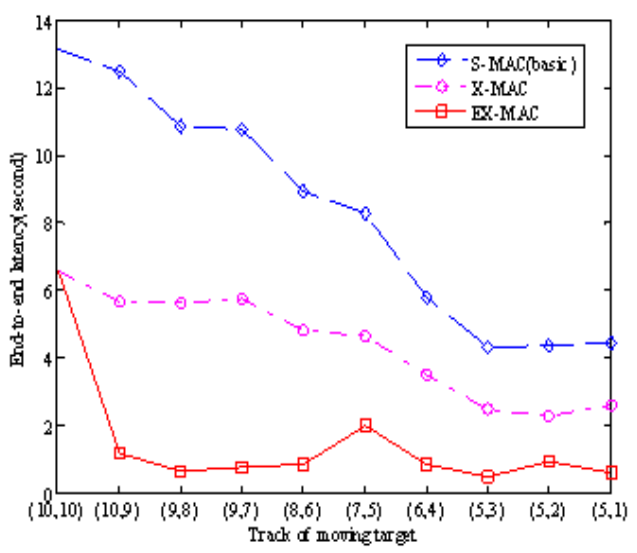

[그림 14] 이벤트 표적 이동에 따른 패킷의 단대단 지연 


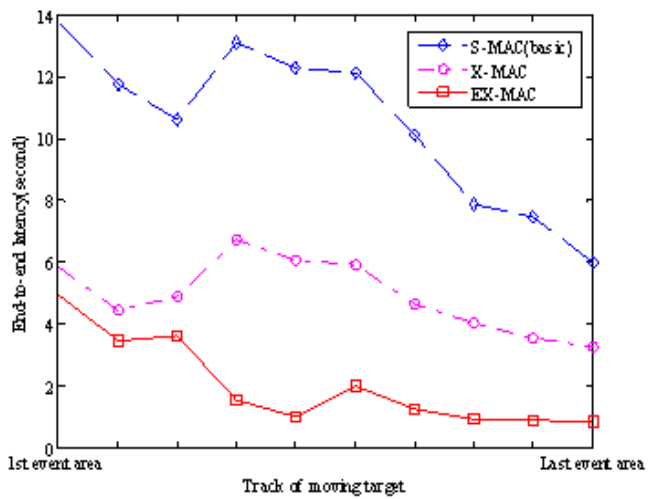

[그림 15] 세 개의 표적 이동에 따른 패킷의 단대단 지연

그림 15 는 시뮬레이션과 같은 환경에서 세 개의 이벤 트를 이동시켰을 때 나온 결과이다. 세 개의 이벤트를 일 정 시간 간격으로 1 홉 범위 안에서 이동 발생시켰으며, 이벤트 발생 후 세 이벤트의 데이터 모두 싱크로 전송 되 었을 때의 단대단 지연을 측정하였다. 세 개의 이동성 이 벤트 발생 시 EX-MAC은 첫 이벤트 발생 지역에서 약 2 홉 범위에서 X-MAC보다 약간의 시간 지연이 줄어 들었 으며 그 이상에서는 상당량의 지연이 줄어들었다. 약 2홉 범위까지 전송지연이 높은 이유는 3 개의 이벤트 발생으 로 인한 채널 점유에 따른 전송 지연 및 $\mathrm{EDCR}$ 수행에 의 한 것으로 여겨진다.

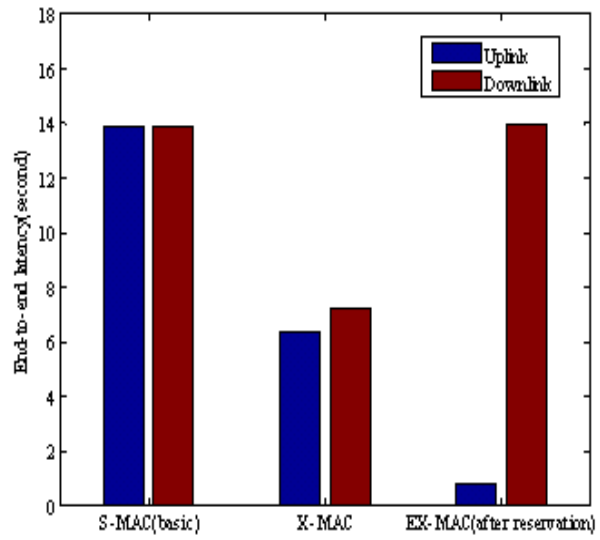

[그림 16] 업링크/다운링크의 단대단 지연

EX-MAC에서 업링크/다운링크 전송 지연의 비대칭성 은 그림 16 에서 확인된다. S-MAC은 업링크/다운링크 모 두 전송 홉 수에 비례하여 높은 수준의 단대단 지연 성능 을 가지고 있으며, X-MAC은 이의 절반 수준의 업링크/ 다운링크 단대단 지연 성능을 보인다. 예약 이후
$\mathrm{EX}-\mathrm{MAC}$ 은 업링크 방향으로는 1홉 정도의 작은 단대단 지연을 보이지만, 다운링크 방향으로는 S-MAC수준의 전 송지연이 존재한다.

\section{5. 결론}

최근 센서 네트워크는 감시와 보안, 생태 환경 관찰, 홈 네트워크 분야 등에 많은 연구가 이루어지고 있다. 특 히 센서 네트워크의 감시와 보안 분야는 군사용에 그 적 용이 활발한 추세이다. 센서 네트워크 군사용 목적에 적 용할 때 가장 중요한 요소로는 빠른 정보 수집과 데이터 의 높은 신뢰도가 있다. 그러나 센서 네트워크의 가장 큰 제약 중 하나인 저전력 소모 특성은 위의 두 가지 요소를 만족시키는데 많은 걸림돌이 되고 있다.

본 논문에서는 기존 센서 네트워크 duty-cycle을 사용 한 $\mathrm{MAC}$ 프로토콜의 높은 단대단 지연 문제 해결을 위한 EX-MAC 프로토콜을 제안하였다. 이벤트는 지역적, 시 간적으로 높은 상관관계를 가지고 발생되기 때문에 이를 고려하여 $\mathrm{EX}-\mathrm{MAC}$ 은 첫 이벤트 데이터 전송에서 경로 노드의 주기 변경 방식을 사용하였다. 이는 연속적인 이 벤트 데이터 전송에서 낮은 단대단 지연을 보장하였다.

또한, 감시 정찰 등의 표적 이동 상황에서 낮은 단대단 지연을 보장하고자 $\mathrm{EDOP}$ 와 $\mathrm{EDSP}$ 의 두 가지 경로 변경 알고리즘을 적용하였다. $\mathrm{EDOP}$ 와 $\mathrm{EDSP}$ 는 네트워크의 오 버헤드를 증가 시키지 않으면서도 기존 예약 경로 사용 이 가능하게 함으로써 보다 효율적인 단대단 지연 성능 을 보장하였다. 이와 같은 $\mathrm{EX}-\mathrm{MAC}$ 의 우수한 단대단 지 연 성능은 시뮬레이션 과정을 통하여 확인 하였으며, 에 너지 효율성 측면에서도 성능이 향상 되었음을 확인되었다.

유비쿼터스의 관심도가 높아짐에 따라 센서 네트워크 는 각광받는 통신 분야로 성장하고 있다. 하지만 기존 네 트워크와 다른 센서 네트워크의 특성으로 인하여 고효율, 저가격의 하드웨어 개발뿐 아니라 소프트웨어 측면에서 많은 발전이 요구되고 있다. 센서 네트워크의 다양한 응 용 분야 적용과 그에 알맞은 프로토콜의 연구는 미래 유 비쿼터스 환경으로 진화하는데 있어 중요한 밑거름이 될 것이다.

\section{참고문헌}

[1] T.V. Dam and K. Langendoen, "An Adaptive Energy-Efficient MAC Protocol for Wireless Sensor Networks", The First ACM Conferenceon Embedded 
Networked Sensor Systems (Sensys'03), Los Angeles, CA, USA, November, 2003.

[2] G. Halkes, T. V. Dam, and K. Langendoen., "Comparing energy-saving mac protocols for wireless sensor networks", ACM Mobile Networks and Applications, 10(5): 783-791, 2005.

[3] J. Ding, K. Sivalingam, R. Kashyapa, L. J. Chuan, "A multi-layered architecture and protocols for large-scale wireless sensor networks", IEEE 58th Vehicular Technology Conference, 2003, Volume: 3, Pages:1443 - 1447, 6-9, 2003.

[4] G. Halkes, T. V. Dam, and K. Langendoen, "Comparing energy-saving mac protocols for wireless sensor networks", ACM Mobile Networks and Applications, 10(5):783-791, 2005.

[5] Rhee, I., Warrier, A., Aia, M., Min, J., “ Z-MAC: A Hybrid MAC for Wireless Sensor Networks", In: Proc. of the ACM SenSys Conf., San Diego, CA pp 90-101, 2005.

[6] Chipcon cc 1000 radios. http://www.chipcon.com.

[7] Chipcon cc 2500 radios. http://www.chipcon.com.

[8] W. Ye, J. Heidemann, and D. Estrin, "An energyefficient mac protocol for wireless sensor networks", In 21st International Annual Joint Conference of the IEEE Computer and Communications Societies (INFOCOM' 02), New York, NY, USA, 2002.

[9] T. van Dam and K. Langendoen., "An adaptive energyefficient mac protocol for wireless sensor networks", In 1st ACM Conference on Embedded Networked Sensor Systems (SenSys), PP 171-180, 2003.

[10] G. Lu, B. Krishnamachari, C.S. Raghavendra, "An adaptive energyefficient and low-latency MAC for data gathering in wireless sensor networks", Proceedings of 18th International Parallel and Distributed Processing Symposium, Pages: 224, 26-30, 2004.

[11] J. Polastre, J. Hill, and D. Culler, "Versatile low power media access for wireless sensor networks", In The Second ACM Conference on Embedded Networked Sensor Systems (SenSys), PP 95-107, 2004.

[12] A. El-Hoiydi and J. Decotignie, "Low power downlink mac protocols for infrastructure wireless sensor networks", ACM Mobile Networks and Applications, 10(5):675-690, 2005.

[13] Buettner, M., Yee, G.V., Anderson, E., Han, R., "X-MAC: A Short Preamble MAC Protocol for Duty-Cycled Wireless Sensor Networks.", In: Proceedings of the fourth ACM SenSts Conference, Boulder, CO, USA, November, 2006.
홍 성 화(Sung-Hwa Hong)

[정회원]

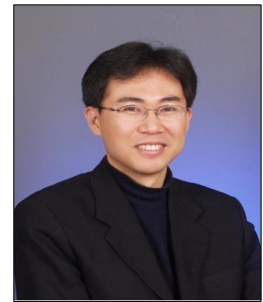

- 1996년 2월 : 고려대학교 컴퓨터 학과 (이학사)

- 2002년 8월 : 한국항공대학교 정 보통신학과 (공학학사)

- 2008년 8월 : 고려대학교 전자컴 퓨터공학과 (공학학박사)

- 1997년 12월 2000년 4월 : 동 원시스템즈 연구원

- 2009년 3월 현재 : 동양미래대학 전산학부 전임강사

<관심분야>

무선네트워크, 홈네트워크, 임베디드 시스템

\section{정 석 용(Suk-Yong Jung)}

[종신회원]

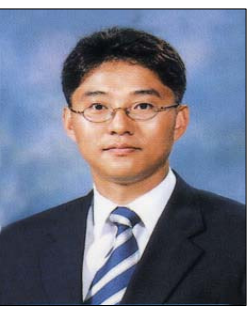

- 1987년 8월 : 서울대학교 (이학 사)

- 1993년 8월 : 한국과학기술원 (공학석사)

- 2004년 8월 : 아주대학교 (공학 박사)

- 1987년 1월 1996년 2월 : LG 정보통신 연구원

- 1986년 3월 현재 : 동양미래대학 전산학부 조교수

<관심분야>

데이터 통신, 내장형 시스템, 정보 관리 